\section{Glyzerin, freies}

K. J. Lackner ${ }^{1}$ und D. Peetz ${ }^{2}$

${ }^{1}$ Institut für Klinische Chemie und Laboratoriumsmedizin, Universitätsmedizin Mainz, Mainz, Deutschland

${ }^{2}$ Institut für Labormedizin, Helios Klinikum Berlin-Buch, Berlin, Deutschland

\section{Englischer Begriff glycerol}

Definition Propanabkömmling mit 3 Hydroxygruppen.

Struktur $\mathrm{C}_{3} \mathrm{H}_{8} \mathrm{O}_{3}$. Strukturformel:

$$
\begin{array}{r}
\mathrm{H}_{2} \mathrm{C}-\mathrm{OH} \\
\mathrm{HC}-\mathrm{OH} \\
\mathrm{H}_{2} \mathrm{C}-\mathrm{OH}
\end{array}
$$

Molmasse $92,09 \mathrm{~g}$.

Synthese - Verteilung - Abbau - Elimination Glyzerin ist ein zentrales Molekül des Kohlenhydrat- und Fettstoffwechsels. Es ist Bestandteil von Triglyzeriden (s. $>$ Triglyzeride) und Phospholipiden (s. $>$ Phospholipide). Im Blut kommen geringe Mengen freien Glyzerins vor, die diagnostisch keine Bedeutung erlangt haben, bei der Bestimmung von Triglyzeriden aber stören können.

\section{Literatur}

Löffler G, Petrides PE (Hrsg) (2003) Biochemie und Pathobiochemie, 7. Aufl. Springer, Berlin/Heidelberg/New York 